VI Congresso Brasileiro de Informática na Educação (CBIE 2017)

Anais do XXIII Workshop de Informática na Escola (WIE 2017)

\title{
Novel: Um Jogo Educativo para Aprendizagem de Ortografia
}

\author{
Italo M. de Novais ${ }^{1}$, Leandro L. Ramos ${ }^{1}$, Pablo F. Matos ${ }^{2}$, Josilene D. S. Pereira \\ ${ }^{1}$ Discente Superior em BSI, ${ }^{2}$ Docente de Informática, ${ }^{3}$ Docente de Língua Portuguesa \\ ${ }^{123}$ Instituto Federal de Educação, Ciência e Tecnologia da Bahia (IFBA) \\ Av. Amazonas, 3150, Zabelê - 45.075-265 - Vitória da Conquista - BA - Brasil \\ \{italomirandadenovais, leandrolopesramos1992, pablofmatos, \\ josidomingues.ifba\} @gmail.com
}

\begin{abstract}
In general, students of the Portuguese Language present difficulties to use orthographic rules, especially in formal contexts that require the use of correct spelling of words. To solve this problem, alternative teaching techniques may be adopted, such as educational games. This paper describes the development and evaluation, by way of a case study, of the educational game Novel that deals with orthographic norms of Brazilian Portuguese in a playful way. The case study revealed the use of Novel by students contributes significantly to the learning spelling, considering that the average scores of the students who used the software were higher than those who did not use it.
\end{abstract}

Resumo. Estudantes de língua portuguesa, de uma maneira geral, apresentam dificuldades para empregar regras ortográficas, especialmente em contextos formais que exigem o uso da grafia correta das palavras. Para solucionar esse problema, técnicas alternativas de ensino podem ser adotadas, como os jogos educativos. Este artigo descreve o desenvolvimento e a avaliação, por meio de um estudo de caso, do jogo educativo Novel que aborda normas ortográficas do português brasileiro de forma lúdica. O estudo de caso revelou que o uso do Novel pelos estudantes contribui significativamente para a aprendizagem da ortografia, considerando que a média de acertos dos estudantes que utilizaram o software foi maior do que a dos que não o utilizaram.

\section{Introdução}

Leitura e escrita são atividades fundamentais nas demandas das práticas sociais em nossa sociedade. Dessa forma, um dos objetivos mais importantes que o ensino de língua portuguesa deve assumir na escola é proporcionar ao estudante a apropriação da escrita, a fim de utilizá-la, de maneira eficiente, nas diversas situações sociocomunicativas. Um dos domínios de apropriação da escrita consiste, especialmente em contextos formais, no emprego das normas ortográficas. Nesse aspecto, muitos estudantes brasileiros apresentam dificuldades de escrita. Bizzochi (2000) afirma que essa dificuldade ocorre devido às inúmeras regras complexas e pela grande quantidade de exceções da norma, que requerem muita prática para serem memorizadas. Apesar do INEP (2015) mostrar que houve um aumento de $27,2 \%$ para $27,5 \%$ no desempenho dos alunos do ensino médio, em relação à língua portuguesa, entre os anos de 2013 e 2015, ainda falta muito para alcançar as metas estipuladas pelo Plano Nacional de Educação [Brasil 2014], a saber: desempenho em leitura e escrita igual a 70\% até 2020.

Considerando a necessidade de criar estratégias diferenciadas para a aprendizagem das normas ortográficas da língua portuguesa pelos estudantes brasileiros, 
técnicas alternativas de ensino-aprendizagem, como os jogos educativos, podem ser adotadas. O jogo educativo é uma forma de motivar o processo de aprendizagem de maneira lúdica. Pode-se dizer que "os jogos educativos são excelentes ferramentas que o docente pode utilizar no processo de ensino aprendizagem, visto que eles contribuem para o enriquecimento intelectual e social do educando" [Lima, Silva e Silva 2009].

Nesse contexto, este artigo propõe o jogo educativo Novel como recurso didático e ferramenta de auxílio ao aprendizado autônomo de regras ortográficas, cujo objetivo é facilitar a compreensão dessas normas e, por consequência, melhorar o desempenho dos alunos em práticas sociais de escrita que exigem a utilização da ortografia. São utilizados elementos como badges (medalhas ou conquistas), pontos, progresso, e narrativa para fazer com que os usuários sintam-se motivados a realizar as tarefas. $\mathrm{O}$ restante do artigo está estruturado da seguinte forma: Seção 2, trabalhos correlatos; Seção 3, descrição das características e do desenvolvimento do jogo educativo Novel; Seção 4, descrição do estudo de caso e Seção 5, considerações finais e trabalhos futuros.

\section{Trabalhos Correlatos}

Barbosa et al. (2008) criaram o Objeto de Aprendizagem Análise Morfológica e Sintática, que busca facilitar a compreensão da gramática por meio de atividades lúdicas. $\mathrm{O}$ jogo fornece perguntas para que o jogador procure acertar mais questões em menos tempo. Para auxiliar os estudantes a lembrarem das regras gramaticais, o jogo disponibiliza um mapa mental. Os autores realizaram um experimento com alunos da rede municipal de ensino da cidade de João Pessoa/PB, com o objetivo de avaliar o impacto do software educativo na aprendizagem significativa da gramática. Segundo os autores, foi possível perceber que os alunos se mostraram muito motivados em aprender utilizando o objeto de aprendizagem. O resultado desse experimento revelou que a maioria dos estudantes conseguiu acertar questões sobre classes gramaticais e funções das palavras. Todavia, grande parte dos alunos não obteve uma boa pontuação em questões que envolviam análise morfossintática.

Outra aplicação desenvolvida com o mesmo intuito é o Jogo Ortográfico Educacional [Paschoal et al. 2014]. Este software, cujo tema é o Novo Acordo Ortográfico estabelecido pelos países de Língua Portuguesa, tem como propósito facilitar a compreensão das regras de acentuação e uso de hífen nas palavras, por meio de desafios, nos quais o usuário deve digitar as palavras de maneira correta para avançar e assim concluir o jogo. Não foram realizados testes para validar o software.

O jogo Digita, desenvolvido por An et al. (2013), é outro exemplo de software educativo cujo tema é a alfabetização, no qual o usuário é convidado a ordenar sílabas e identificar objetos de acordo com o contexto do jogo. Foi realizada a validação do software por um especialista em educação, que respondeu questionários sobre a usabilidade e os requisitos pedagógicos do site, revelando que o objetivo do jogo (colaborar com a alfabetização de crianças) é muito complexo e que novas funcionalidades deveriam ser implementadas.

\section{Novel}

Novel $^{1}$ (significa "aprendiz") é um jogo educativo que foi desenvolvido com o intuito de auxiliar a aprendizagem de regras ortográficas da língua portuguesa. O software é

\footnotetext{
${ }^{1}$ http://novel.conquista.ifba.edu.br
} 
VI Congresso Brasileiro de Informática na Educação (CBIE 2017)

Anais do XXIII Workshop de Informática na Escola (WIE 2017)

composto por 03 (três) níveis, nos quais são apresentadas questões sobre regras ortográficas para os jogadores. Cada nível possui 08 (oito) fases, pelas quais o jogador deve passar para completar o jogo. O primeiro nível, denominado "Palavra", apresenta um conjunto de palavras incompletas, com lacunas que devem ser preenchidas com as letras corretas. O segundo nível, de nome "Texto", exibe textos com palavras incompletas, para que o jogador preencha corretamente. Já o terceiro nível, “Teste”, é composto por questões de múltipla escolha, nas quais o jogador deve marcar as alternativas corretas.

\subsection{Níveis: Palavra, Texto e Teste}

O nível Palavra é o ponto inicial do jogo, no qual são exibidas as regras ortográficas em cada fase. É neste nível que o usuário aprende, por exemplo, quando se usam as letras $s$, $x$ e $z$ em sílabas que possuem som de /z/, como em "casa", "azeite" e "exato". Como o nível Palavra tem a finalidade de ensinar, o jogador pode visualizar as regras enquanto preenche as lacunas das palavras. Em cada fase, são sorteadas 05 (cinco) palavras aleatórias, que são exibidas ao jogador junto com suas definições, permitindo que ele possa preencher as lacunas de maneira correta, como exibido na Figura 1. A definição da palavra pode fazer a diferença na letra que o jogador escolher, como no caso de "chá" (bebida) e " $x a ́$ " (título dado aos antigos monarcas persas).

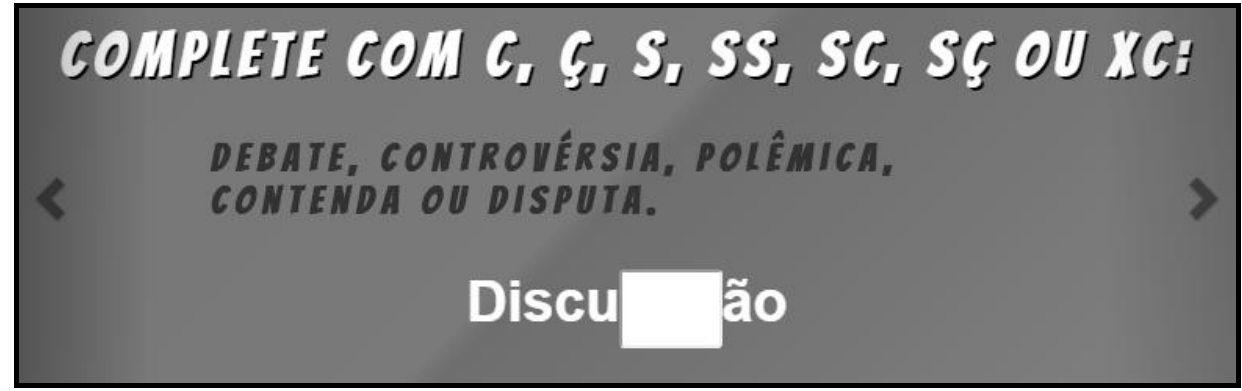

Figura 1. Nível Palavra. Fonte: Elaborado pelo autor

Quando o jogador passa a conhecer as regras, ele pode aplicá-las em contextos diferentes. É deste princípio que parte o nível Texto, propondo ao jogador textos com palavras em contextos variados, nos quais ele precisa preencher lacunas das palavras, assim como no nível Palavra. A diferença é que, nos textos, podem aparecer elementos como homônimos e parônimos que podem confundir o jogador, exigindo maior concentração e análise para o correto preenchimento das lacunas. Como o usuário precisa conhecer previamente as regras, as fases do nível Texto são liberadas à medida que elas são estudadas no nível Palavra. Nesse nível, cada fase possui um texto relacionado a uma regra ortográfica e que é sorteado aleatoriamente (Figura 2).

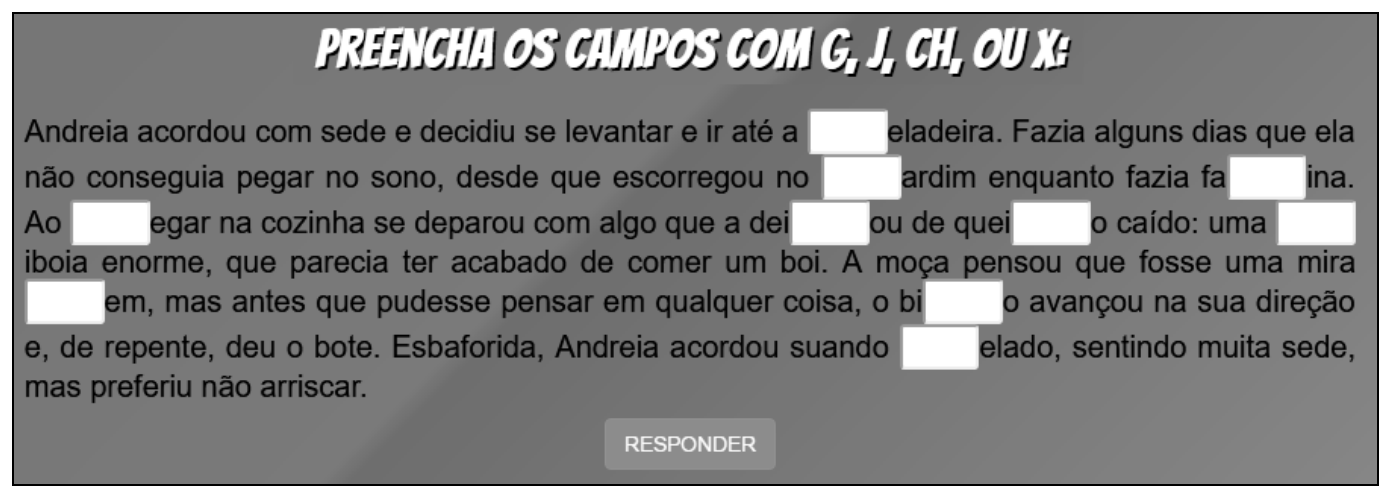

Figura 2. Nível Texto. Fonte: Elaborado pelo autor 
VI Congresso Brasileiro de Informática na Educação (CBIE 2017)

Anais do XXIII Workshop de Informática na Escola (WIE 2017)

O nível Teste simula situações de provas de vestibulares e concursos, os quais são compostos por questões de múltipla escolha, que exigem de quem as responde uma análise mais profunda, para detectar possíveis ocorrências de erros propositais que são justamente propostos para gerar uma série de dúvidas no jogador. É válido salientar que o próprio formato das questões pode fazer com que o jogador fique em dúvida no momento de escolher a alternativa correta. Busca-se, desta maneira, proporcionar ao jogador, no nível Teste, situações semelhantes às encontradas na vida real. Assim como acontece com o nível Texto, as fases do nível Teste são desbloqueadas à medida que o jogador estuda as regras no nível Palavra. Para tornar mais difícil este nível, o número de questões de múltipla escolha aumenta à proporção que o jogador avança no jogo, sendo que, nas quatro primeiras fases, são exibidas 04 (quatro) questões, enquanto que, na quinta e sexta fases, são exibidas 08 (oito) questões. Na sétima e oitava fases, são exibidas 16 (dezesseis) questões. Uma das fases do nível Teste é exibida na Figura 3.

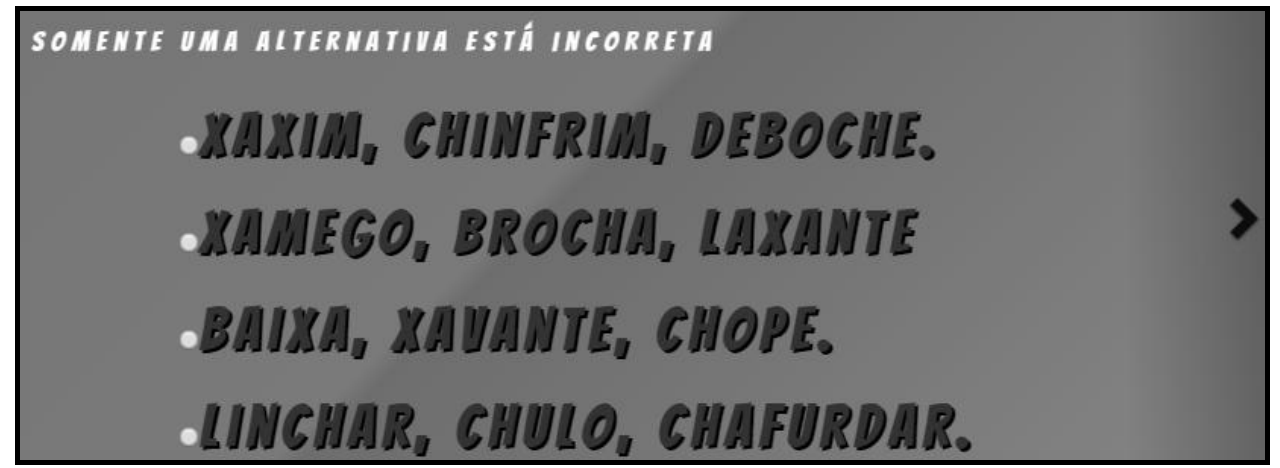

Figura 3. Nível Teste. Fonte: Elaborado pelo autor

\subsection{Narrativa e Pontuação}

Com o intuito de fazer com que o jogador se sinta motivado a jogar e praticar as regras ortográficas, foi criada uma narrativa contada no formato de história em quadrinhos, que é exibida ao jogador no decorrer do jogo. A narrativa conta a história de 04 (quatro) jovens, Cecília, Veríssimo, Clarice e Graciliano, que entram na Academia de Novéis, onde aprendem regras gramaticais e as utilizam para salvar sua vila dos ataques do vilão, chamado Moncoso. Na Figura 4, pode-se conferir uma cena dessa história em quadrinhos.
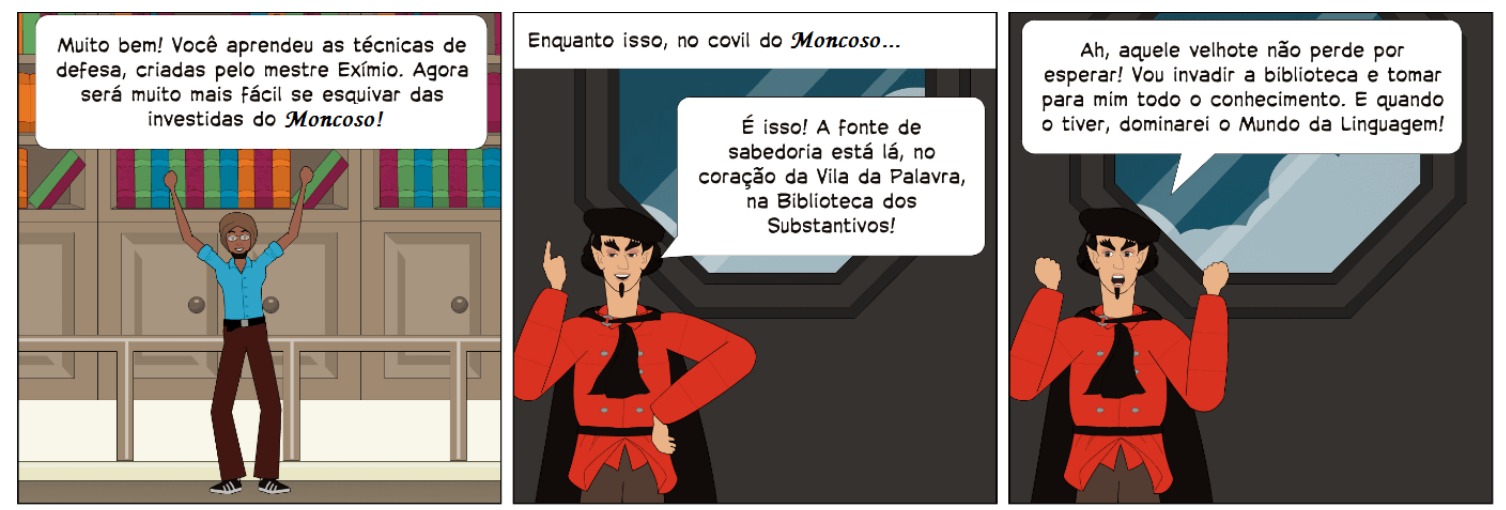

Figura 4. História em quadrinhos. Fonte: Elaborado pelo autor

Outra forma de motivar o usuário a continuar jogando é a pontuação. Cada vez que o jogador passa por uma fase, ele recebe uma quantidade de pontos que depende do número de acertos obtidos. No nível Palavra, o jogador ganha 10 pontos por questão 
acertada, enquanto no nível Texto ganha 20 e, no nível Teste, ganha 30. Ao acumular pontos, que, no Novel, são chamados de "experiência", o jogador alcança "conquistas". As conquistas representam feitos heroicos alcançados pelos personagens do jogo ao longo da história. Cada vez que um jogador alcança uma Conquista, ele recebe medalhas, que estão relacionadas com temas da gramática como, por exemplo, "Encontrou o Pergaminho dos Substantivos". Ao todo, são 20 (vinte) medalhas que o jogador pode ganhar. Dessa forma, pretende-se que o jogador continue jogando, mesmo após finalizar a história, para que ganhe todas as medalhas, fazendo com que ele continue treinando as regras enquanto joga as fases. Um exemplo de medalha é exibido na Figura 5.

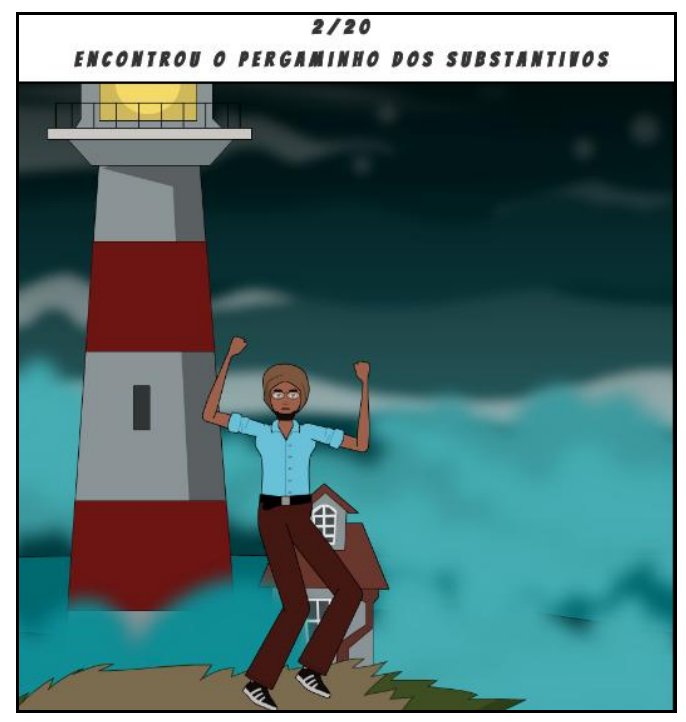

Figura 5. Exemplo de medalha. Fonte: Elaborado pelo autor

\subsection{Desenvolvimento do Software}

O Novel foi desenvolvido utilizando o padrão arquitetural Model-View-Controller [Gamma et al. 2000], no qual é possível dividir o código em camadas, o que torna sua compreensão e manutenção simplificadas. A camada Model contém as classes que compõem a lógica do jogo, suas regras e funções que são o núcleo do software. A camada Controller é formada pelas classes que realizam a troca de dados entre os Models e as Views. O objetivo dela é preparar os dados, direcioná-los para as classes corretas e fazer a chamada dos seus respectivos módulos. A camada View é composta pelas telas que são exibidas aos usuários. Essas páginas recebem os dados da camada Controller e os exibem aos jogadores, recebendo também as entradas e repassando-as à camada Controller.

Para realizar o desenvolvimento do Novel, foi escolhida a plataforma web, para que sua disponibilização e utilização fosse ampliada. Procurou-se desenvolver as telas do jogo adaptáveis (i.e., telas responsivas) aos mais variados tamanhos de tela. As linguagens utilizadas no desenvolvimento foram HTML, PHP, JavaScript e CSS, com o auxílio dos frameworks CodeIgniter e Bootstrap. O Sistema de Gerenciamento de Banco de Dados escolhido na implementação foi o MariaDB, por se tratar de uma ferramenta open source robusta, rápida e escalável.

\section{Estudo de Caso}

O aprendizado dos estudantes, ao utilizarem o software para estudar ortografia, foi averiguado por meio de estudo de caso. Os participantes da pesquisa foram 31 (trinta e 
um) alunos de uma turma do primeiro ano do ensino médio. Em um primeiro momento, todos os estudantes responderam a um questionário que propunha questões sobre regras ortográficas presentes no software, para medir seu desempenho antes de participarem das próximas etapas. A turma foi dividida, de maneira aleatória, em 02 (dois) grupos incialmente: um, com 15 (quinze) alunos, e outro, com 16 (dezesseis). Alguns participantes, entretanto, faltaram nos dias marcados para a realização da etapa subsequente e os grupos ficaram divididos da seguinte forma: Grupo 1, com 18 participantes; Grupo 2, com 13 participantes.

O Grupo 1 foi utilizado como grupo de controle, participando de uma aula expositiva com um professor de língua portuguesa, enquanto o Grupo 2 utilizou o software, que apresentava as mesmas regras explicadas pelo professor. O objetivo dessa opção metodológica era aplicar, na etapa seguinte, depois da aula expositiva e da utilização do jogo, o questionário sobre as regras ortográficas, para que se pudesse confrontar os desempenhos dos dois grupos. Nesta etapa do estudo, ocorreram as aplicações de dois questionários: um, sobre regras ortográficas, e outro, sobre as características do software. O resumo das características desse estudo de caso pode ser analisado na Tabela 1.

Tabela 1. Etapas do Estudo de Caso

\begin{tabular}{|c|l|l|l|}
\hline Grupo & \multicolumn{1}{|c|}{ Primeira etapa } & \multicolumn{1}{|c|}{ Segunda etapa } & \multicolumn{1}{|c|}{ Terceira etapa } \\
\hline 1 & $\begin{array}{l}\text { Questionário sobre } \\
\text { ortografia }\end{array}$ & $\begin{array}{l}\text { Aula expositiva com } \\
\text { professor de língua } \\
\text { portuguesa }\end{array}$ & $\begin{array}{l}\text { Questionário sobre } \\
\text { ortografia }\end{array}$ \\
\hline 2 & $\begin{array}{l}\text { Questionário sobre } \\
\text { ortografia }\end{array}$ & Utilização do Novel & $\begin{array}{l}\text { Questionários sobre } \\
\text { ortografia e avaliação } \\
\text { do software }\end{array}$ \\
\hline
\end{tabular}

Ao final da segunda aplicação do questionário sobre ortografia, os estudantes foram incentivados a avaliar a metodologia utilizada no estudo de caso. Em ambos os grupos, os alunos disseram que o estudo foi demorado e cansativo. Os alunos do Grupo 1 afirmaram que se sentiram cansados durante a explicação do professor, mas que adquiriram mais confiança ao responder às questões após a aula. Os alunos do Grupo 2 afirmaram que, no segundo questionário, já estavam cansados e relataram que ficaram com "preguiça de pensar nas questões". Sobre o software, os participantes afirmaram que o Novel foi bem elaborado, com uma história divertida e questões desafiadoras.

\subsection{Avaliação do Aprendizado}

Os questionários sobre ortografia, aplicados no início e no final do estudo de caso, foram utilizados para medir a média de acertos dos participantes da pesquisa. Foram confrontadas as médias de acertos antes e depois tanto da aula do professor de língua portuguesa quanto da aplicação do software Novel, o que permitiu avaliar as porcentagens de aprendizado dos estudantes que aumentaram, mantiveram e/ou regrediram suas médias.

No Grupo 1, 33,33\% dos estudantes obtiveram um aumento na média de acertos, $22,22 \%$ mantiveram as mesmas médias nas duas aplicações do questionário e 44,44\% regrediram (Figura 6a). Apesar da diminuição da média de acertos da maioria dos estudantes do Grupo 1, houve um aumento na média geral, de 54,86\% antes da aula para $56,02 \%$ depois de aula. Esta melhora na média geral aconteceu porque a média de aumento foi de $11,11 \%$, enquanto a média de regressão foi de $5,73 \%$. 
VI Congresso Brasileiro de Informática na Educação (CBIE 2017)

Anais do XXIII Workshop de Informática na Escola (WIE 2017)

No Grupo 2, 53,8\% dos estudantes obtiveram um aumento na média de acertos, $7,7 \%$ mantiveram as mesmas médias nas duas aplicações do questionário e 38,5\% regrediram (Figura 6b). Apesar do aumento da média de acertos da maioria dos estudantes do Grupo 2, houve uma diminuição na média geral de 74,68\%, antes do jogo, para $73,40 \%$ depois do jogo. Esta diminuição da média geral se deve ao fato de que a média de aumento foi de $7,74 \%$, enquanto a média de regressão foi de $14,17 \%$.

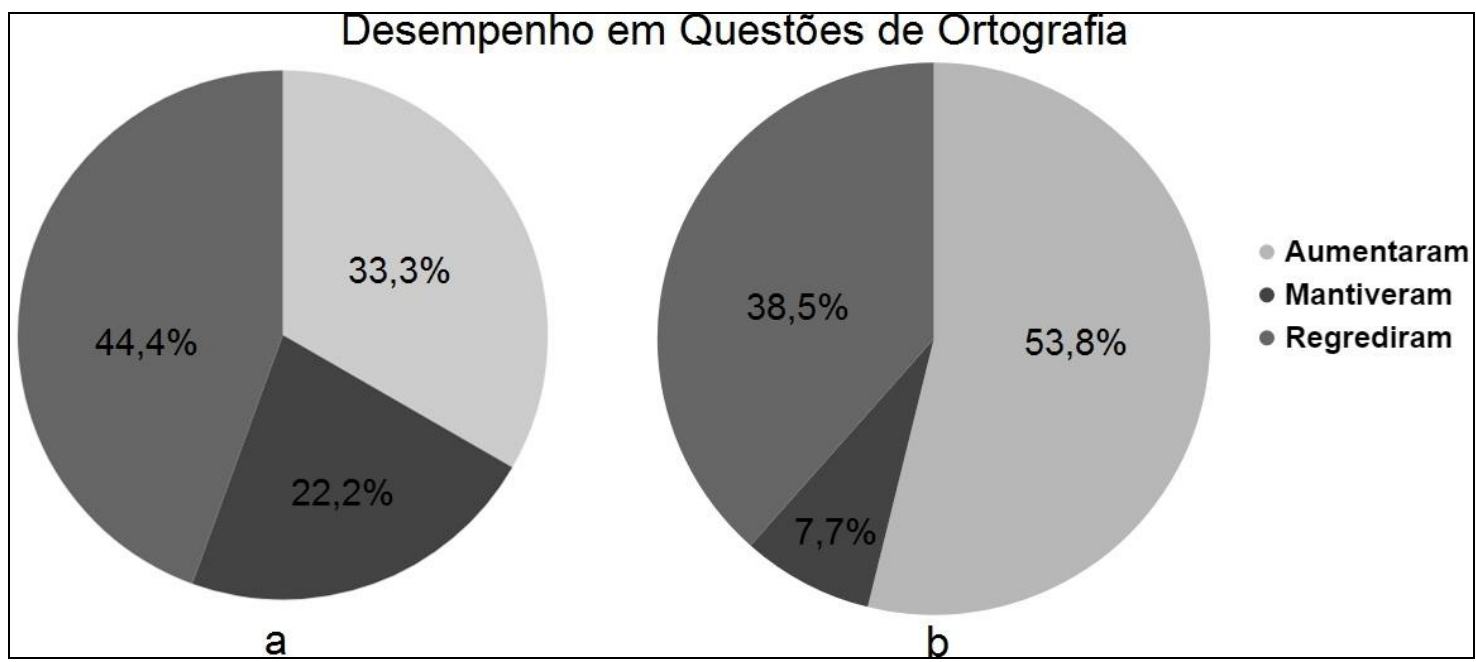

Figura 6. Desempenho dos alunos em questões de ortografia: (a) Grupo 1 e (b) Grupo 2. Fonte: Elaborado pelo autor.

\subsection{Teste de Hipótese}

A hipótese assumida nesta pesquisa é: a média de acertos em questões de ortografia de estudantes que estudam por meio do jogo educativo é igual à dos estudantes que estudam pelo método tradicional por meio de aula expositiva com um professor de língua portuguesa. Para realizar o teste de hipótese, foram utilizadas as respostas da segunda aplicação do questionário sobre ortografia. Os números de acertos dos estudantes em cada grupo foram:

- Grupo 1: $(9,10,10,10,12,12,12,13,13,13,14,14,15,15,17,17,18,18)$;

- Grupo 2: $(12,12,16,16,17,18,18,18,19,19,20,22,22)$.

Dessa forma, as duas amostras foram submetidas ao teste de Shapiro-Wilk [Portal Action 2017], para testar a Normalidade das distribuições. O teste mostrou que as duas amostras possuem distribuição normal, como pode ser observado na Figura 7.

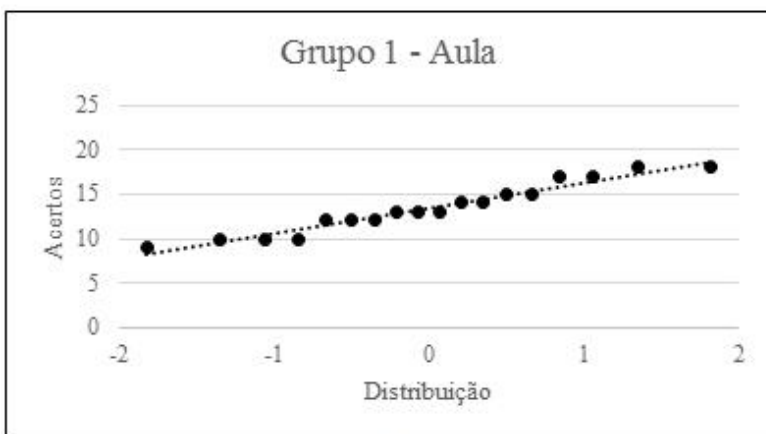

a

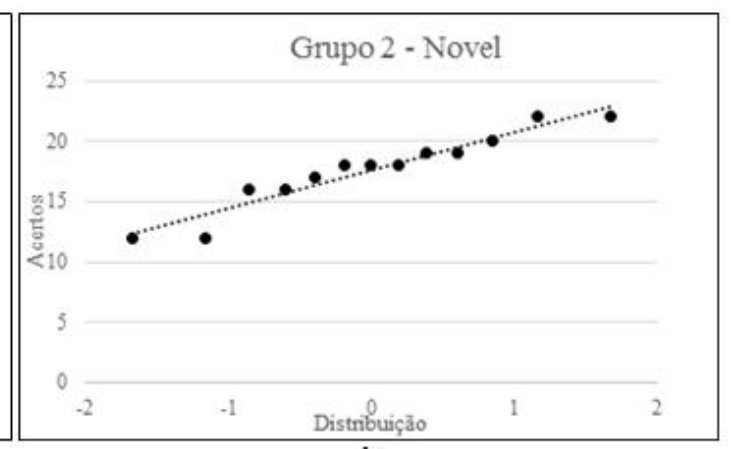

b

Figura 7. Distribuições das médias de acertos dos alunos: (a) Grupo 1 e (b) Grupo 2. Fonte: Elaborado pelo autor 
VI Congresso Brasileiro de Informática na Educação (CBIE 2017)

Anais do XXIII Workshop de Informática na Escola (WIE 2017)

Após a confirmação de que as amostras seguiam uma distribuição Normal, era necessário realizar o teste $\mathrm{F}$ bicaudal, considerando como hipótese nula que as variâncias são iguais, para melhor parametrizar o teste t de Student [Fonseca e Martins 2011], de forma que o teste mais eficaz fosse escolhido. O teste $\mathrm{F}$ revelou que as variâncias das duas amostras são equivalentes, permitindo escolher o teste $t$ de Student para duas amostras independentes, tendo como hipótese nula $\mathrm{H}_{0}$ que a média de acertos dos estudantes que utilizaram o Novel foi igual à média de acertos dos estudantes que assistiram à aula. Os resultados obtidos podem ser visualizados na Tabela 2 .

Tabela 2. Resultados obtidos no teste $t$ de Student

\begin{tabular}{|c|c|c|}
\hline \multicolumn{2}{|c|}{$\begin{array}{c}\text { Teste t para duas amostras independentes } \\
\text { com variâncias equivalentes }\end{array}$} \\
\hline Média & Grupo 1 & Grupo 2 \\
\hline Variância & 13,44 & 17,62 \\
\hline Amostras & 7,91 & 9,76 \\
\hline Variância agrupada & 18 & 13 \\
\hline Hipótese da diferença de média & \multicolumn{2}{|c|}{8,67} \\
\hline Graus de liberdade & \multicolumn{2}{|c|}{0} \\
\hline Estatística T & \multicolumn{2}{|c|}{$-3,89$} \\
\hline $\mathrm{P}(\mathrm{T}<=\mathrm{t})$ unicaudal & \multicolumn{2}{|c|}{0,00027} \\
\hline $\mathrm{t}$ Crítico unicaudal & \multicolumn{2}{|c|}{1,70} \\
\hline $\mathrm{P}(\mathrm{T}<=\mathrm{t})$ bicaudal & \multicolumn{2}{|c|}{0,00054} \\
\hline $\mathrm{t}$ Crítico bicaudal & 2,045 \\
\hline
\end{tabular}

$\mathrm{O}$ resultado do teste foi a rejeição de $\mathrm{H}_{0}$, já que o valor de $\mathrm{T}(-3,89)$ é menor que o valor de $\mathrm{t}$ crítico inferior $(1,70)$. Portanto, pode-se afirmar que a diferença entre a média de acertos dos dois grupos é superior a zero. A média de acertos do Grupo 1 é 13,44, enquanto a média de acertos do Grupo 2 é 17,62. A diferença entre as médias é igual a 4,18, um número significativamente superior a zero. Analisando a Figura 8 , fica evidente a diferença entre as notas dos Grupos 1 e 2. Os estudantes que utilizaram o Novel possuem notas maiores do que os estudantes que participaram somente da aula com o professor de língua portuguesa.

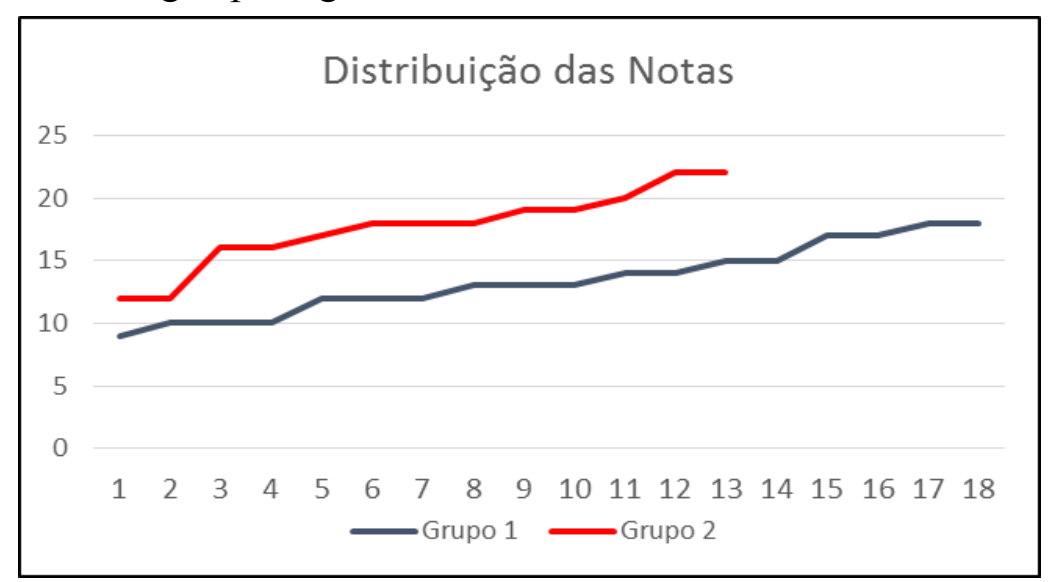

Figura 8. Comparação das médias de acertos dos alunos: (a) Grupo 1 (b) e Grupo 2. Fonte: Elaborado pelo autor

Após a realização do teste $\mathrm{t}$ de Student, foram calculados os intervalos de confiança (Figura 9), baseados na estatística t com nível de confiança em 95\%, para as duas amostras, resultando nos seguintes valores de limite inferior e limite superior, respectivamente: Grupo $1[12,046 ; 14,843]$ e Grupo 2 [15,728; 19,503]. Assim, é 
VI Congresso Brasileiro de Informática na Educação (CBIE 2017)

Anais do XXIII Workshop de Informática na Escola (WIE 2017)

possível estabelecer, para o teste realizado, um nível de confiança de $95 \%$, uma vez que as médias dos dois grupos estão entre os limites críticos inferior e superior.

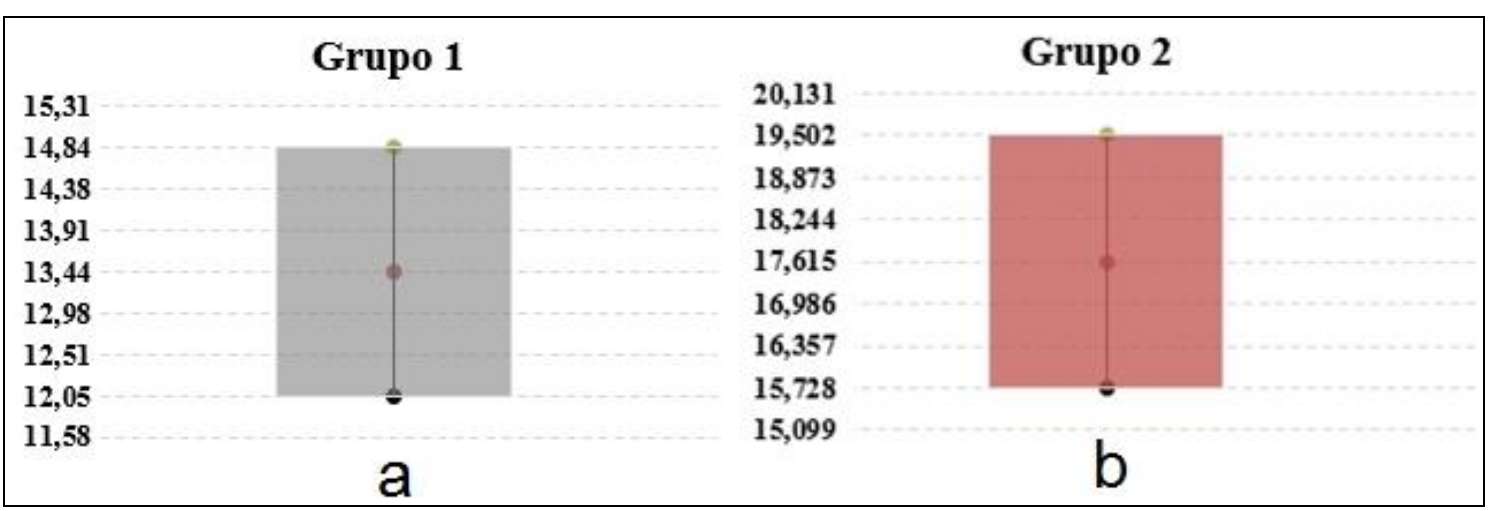

Figura 9. Intervalos de confiança: (a) Grupo 1 e (b) Grupo 2. Fonte: Elaborado pelo autor

\subsection{Avaliação do Software}

Com o objetivo de avaliar o software criado, os participantes do Grupo 2 foram convidados a responder ao formulário de avaliação do software, que possuía perguntas sobre as características do jogo e seu conteúdo. Uma análise resumida dos resultados pode ser vista na Tabela 3 .

Tabela 3. Análise da avaliação do software

\begin{tabular}{|l|c|c|c|c|c|}
\hline \multicolumn{1}{|c|}{ Questionamento } & $\begin{array}{c}\text { Concorda } \\
\text { Totalmente }\end{array}$ & $\begin{array}{c}\text { Concorda } \\
\text { Parcialmente }\end{array}$ & Indiferente & $\begin{array}{c}\text { Discorda } \\
\text { Parcialmente }\end{array}$ & $\begin{array}{c}\text { Discorda } \\
\text { Totalmente }\end{array}$ \\
\hline $\begin{array}{l}\text { O Novel é útil para } \\
\text { o aprendizado de } \\
\text { ortografia }\end{array}$ & $69,23 \%$ & $15,38 \%$ & $15,38 \%$ & $0 \%$ & $0 \%$ \\
\hline O Novel é divertido & $84,62 \%$ & $7,7 \%$ & $7,7 \%$ & $0 \%$ & $0 \%$ \\
\hline $\begin{array}{l}\text { As explicações dos } \\
\text { conteúdos são } \\
\text { claras e fáceis de se } \\
\text { entender }\end{array}$ & $61,54 \%$ & $38,46 \%$ & $0 \%$ & $0 \%$ & $0 \%$ \\
\hline $\begin{array}{l}\text { O Novel prende a } \\
\text { atenção do jogador }\end{array}$ & $46,15 \%$ & $46,15 \%$ & $7,69 \%$ & $0 \%$ & $0 \%$ \\
\hline $\begin{array}{l}\text { O conteúdo } \\
\text { apresentado pelo } \\
\text { jogo é relevante }\end{array}$ & $30,8 \%$ & $61,5 \%$ & $0 \%$ & $7,7 \%$ & $0 \%$ \\
\hline $\begin{array}{l}\text { É possível aplicar o } \\
\text { conteúdo nas } \\
\text { situações do } \\
\text { cotidiano }\end{array}$ & $38,5 \%$ & $61,5 \%$ & $0 \%$ & $0 \%$ & $0 \%$ \\
\hline $\begin{array}{l}\text { Recomendaria o } \\
\text { Novel }\end{array}$ & $84,6 \%$ & $7,7 \%$ & $0 \%$ & $7,7 \%$ & $0 \%$ \\
\hline
\end{tabular}

A análise das respostas dos participantes permite afirmar que a utilização do software no estudo de regras ortográficas tem como vantagens: a utilidade para o aprendizado (84,6\% concordam), a diversão (92,3\% concordam), os desafios proporcionados ao jogador, motivando-o no estudo da ortografia da língua portuguesa, devido à atenção (92,3\% concordam), e a aplicação do conteúdo abordado pelo jogo nas situações do cotidiano ( $100 \%$ concordam). A desvantagem observada é a falta de um professor caso o jogador tenha dúvidas sobre o conteúdo. 
VI Congresso Brasileiro de Informática na Educação (CBIE 2017)

Anais do XXIII Workshop de Informática na Escola (WIE 2017)

\section{Conclusão}

O objetivo deste trabalho foi a criação de um software educativo para auxiliar alunos do ensino médio no estudo autônomo e treino de regras ortográficas, bem como avaliar a usabilidade do software e o desempenho de estudantes em questões de ortografia antes e depois de utilizá-lo. Esses objetivos foram alcançados, visto que o jogo foi implementado, obtendo uma avaliação positiva dos usuários, e foi realizado um estudo de caso para avaliar o desempenho dos estudantes, resultando na rejeição da hipótese de que as médias dos alunos que utilizaram o software seria igual à dos alunos que participaram de uma aula expositiva sobre ortografia. Como diferencial em relação aos trabalhos correlatos citados, o Novel traz a explicação dos assuntos abordados no jogo, e não só mapas mentais, como em Barbosa et al. (2008). Ademais, o uso de uma narrativa promove motivação e entretenimento, já que faz com que o jogo deixe de ser apenas um conjunto de questões a serem respondidas. Como trabalhos futuros, possíveis incrementações são previstas, como um módulo administrativo, permitindo a adição de fases e questões ao jogo, além da inclusão de módulos que abordem outros temas da gramática, como pontuação, acentuação, análise sintática e morfológica.

\section{Agradecimentos}

Agradecemos à turma de estudantes do primeiro ano do ensino médio do curso integrado de informática do IFBA, pela participação voluntária no estudo de caso e ao professor de língua portuguesa, Eduardo Matos Santos, por ter participado da pesquisa e concordado em ministrar aula sobre ortografia para o Grupo 1 do estudo de caso.

\section{Material Complementar}

A narrativa, os diagramas (de caso de uso, de classe e de entidade-relacionamento), e os questionários sobre regras ortográficas e da avaliação do Novel podem ser visualizados no endereço http://bit.ly/2wRiNWd.

\section{Referências}

An, D. Y. et al. (2013) Digita: um Jogo Educativo de Apoio ao Processo de Alfabetização Infantil. In: XIX SBIE, pages 154-163.

Barbosa, R. C. et al. (2008) O Jogo Educacional como Recurso Digital e a Aprendizagem Significativa de Gramática. In: XIX SBIE, pages 491-500.

Bizzochi, A. (2000) "A complexidade gramatical do português como possível fator obstrutivo de sua internacionalização", http://bit.ly/2npRSNr.

Brasil. MEC. SASE. (2014) "Planejando a próxima década: Conhecendo as 20 metas do Plano Nacional de Educação", http://bit.ly/1tdckZX.

Fonseca, J. S. e Martins, G. A. (2011) Curso de Estatística. São Paulo: Atlas.

Gamma, E., Helm, R., Johnson, R. e Vlissides, J. (2000). Padrões de Projeto: Soluções Reutilizáveis de Software Orientado a Objetos. Porto Alegre: Bookman.

INEP. (2015) "Indicadores da Educação", http://bit.ly/2mqvE93.

Lima, M. C. F., Silva, V. V. S. e Silva, M. E. L. (2009) Jogos educativos no âmbito educacional: um estudo sobre o uso de jogos no Projeto MAIS da Rede Municipal de Recife, http://bit.ly/1S5csWt, pages 1-27.

Paschoal, L., Bento, T., Velasco, T., Schocair, C. O., Castaneda, R., Oliveira, T. e Ogasawara, E. (2014) JOE: Jogo Ortográfico Educacional. In: XXV SBIE, pages 652-656.

Portal Action. (2017) “Teste de Shapiro-Wilk”, http://bit.ly/2tJZARD. 